\title{
LPS infusion suppresses serum FGF21 levels in healthy adult volunteers
}

\author{
Esben S Lauritzen ${ }^{1,2}$, Nikolaj Rittig ${ }^{1,2}$, Ermina Bach ${ }^{1,2}$, Niels Møller ${ }^{1,2}$ and \\ Mette Bjerre $^{1}$
}

${ }^{1}$ The Medical Research Laboratories, Institute of Clinical Research, Aarhus University, Aarhus C, Denmark ${ }^{2}$ Department of Endocrinology and Internal Medicine, Aarhus University Hospital, Aarhus C, Denmark

2Department of Endocrinology and Internal Medicine, Aarhus University Hospital, Aarhus C, Denmark

\begin{abstract}
Context: During the inflammatory acute phase response, plasma glucose and serum triglycerides are increased in humans. Fibroblast growth factor (FGF) 21 has plasma glucose and lipid-reducing actions, but its role in the acute inflammatory response in human is unknown.

Objective: To investigate circulating levels of FGF21 after lipopolysaccharide (LPS)

infusion.

Design: Two randomized, single-blinded, placebo-controlled crossover trials were used.

Setting: The studies were performed at a university hospital clinical research center.

Patients and interventions: Study 1 (LPS bolus): Eight young, healthy, lean males were investigated two times: (1) after isotonic saline injection and (2) after LPS injection (bolus of $1 \mathrm{ng} / \mathrm{kg}$ ). Each study day lasted $4 \mathrm{~h}$. Study 2 (continuous LPS infusion): Eight, healthy males were investigated two times: (1) during continuously isotonic saline infusion and (2) during continuous LPS infusion $(0.06 \mathrm{ng} / \mathrm{kg} / \mathrm{h})$. Each study day lasted $4 \mathrm{~h}$. Circulating FGF21 levels were quantified every second hour by an immunoassay.

Results: A LPS bolus resulted in a late suppression ( $t=240 \mathrm{~min}$ ) of serum FGF21 $(P=0.035)$.

Continuous LPS infusion revealed no significant effects on FGF21 levels $(P=0.82)$.

Conclusions: Our studies show that a bolus of LPS results in decreased FGF21 levels $4 \mathrm{~h}$ from exposure.
\end{abstract}

\author{
Correspondence \\ should be addressed \\ to E S Lauritzen \\ Email \\ esben.lauritzen@clin.au.dk
}

\section{Introduction}

Fibroblast growth factor 21 (FGF21) is a hormone involved in glucose and lipid homeostasis. It mediates glucose uptake by human adipocytes additively and independently to insulin (1). An increase in FGF21 leads to decreased plasma glucose and triglyceride levels, less hepatic fat and increased insulin sensitivity in animal models $(1,2)$. Reduction of plasma triglycerides and hepatic fat content is probably associated to a reduced hepatic lipogenesis and increased hepatic fatty acid oxidation and ketogenesis (3, 4, 5). FGF21 is predominantly produced in the liver (6) where it is regulated by the transcription factor $\operatorname{PPAR} \alpha(3,5,7)$, (c) 2017 The authors Published by Bioscientifica Ltd but also in the white adipose tissue and skeletal muscle where it is regulated by other transcription factors $(8,9)$. Free fatty acids (FFA) are among some of the substrates that activate PPAR $\alpha$ (10), and in concordance, FGF21 increases during fasting in rodent models (5). In humans, however, fasting is not associated with an increase in FGF21 (11), and the only known stimulus for acutely increased FGF21 levels is fructose and to a lesser extent glucose ingestion (12). Interestingly, increased levels of circulating FGF21 is associated with type 2 diabetes, insulin resistance and obesity $(13,14,15)$. http://www.endocrineconnections.org DOI: 10.1530/EC-16-0103

\author{
Key Words \\ - FGF21 \\ - LPS \\ - inflammation
}


During the acute phase response (APR), temperature and heart rate increase. A temperature $>38^{\circ} \mathrm{C}$ and a heart rate $>90$ beats per minute fulfills the severe inflammatory response syndrome criteria. Also, metabolic and endocrine changes manifest, including an increase in plasma triglycerides and suppression of FFA oxidation (16), an increased insulin resistance and thereby increased glucose levels (17). These changes are initiated for the organism to regain normal function (18). Considering the reducing effects of FGF21 on lipid and glucose metabolism, FGF21 is likely to play an important role in the metabolic reactions to the APR. Whether FGF21 increases counter-regulatory to the metabolic consequences of the APR or decrease assisting these changes to manifest remain unknown. Also, FGF21 was recently reported to improve the outcome of inflammation such as sepsis and pancreatitis in animal models $(19,20)$.

A way to mimic infection in healthy subjects is to inject lipopolysaccharide (LPS) intravenously. LPS, a component of the cell walls of Gram-negative bacteria, activate the innate immune system through Toll-like receptor 4. A study conducted in mice did not reveal any acute effects of LPS infusion on FGF21, but FGF21 increased $16 \mathrm{~h}$ after LPS exposure (19). This effect seems to be consistent in humans where patients with systemic inflammatory response syndrome (SIRS) and sepsis both had increased FGF21 levels (21). We therefore hypothesized that FGF21 would increase acutely in humans during the APR to counter regulate the metabolic consequences and thus improve the outcome. This could potentially describe FGF21 as a new predictive acute phase plasma protein.

\section{Materials and methods}

\section{Study protocol 1}

The study (22) was designed as a randomized placebocontrolled crossover trial with two different study days. Eight males, with BMI between 22 and $26 \mathrm{~kg} / \mathrm{m}^{2}$ (median $23 \mathrm{~kg} / \mathrm{m}^{2}$ ), age between 25 and 32 years (median 26 years), healthy and without regular intake of medicine were investigated two times: (1) After isotonic saline injection (bolus saline) and (2) after an Escherichia coli endotoxin (10,000 USP Endotoxin, lot H0K354; The United States Pharmacopeial Convention, Inc., Rockville, Maryland, USA) bolus injection of $1 \mathrm{ng} / \mathrm{kg}$ of body weight (bolus LPS). Each study day lasted $4 \mathrm{~h}$, and the study days were separated by at least 21 days. The LPS bolus injection was given at $t=0 \mathrm{~min}$. Arterialized blood was sampled at $t=0$, 120 and $240 \mathrm{~min}$ for FGF21 analysis.

\section{Study protocol 2}

The study was (23) designed as a randomized placebocontrolled crossover trial with two different study days. Eight males, with BMI between 22 and $32 \mathrm{~kg} / \mathrm{m}^{2}$ (median 25), age between 50 and 67 years (median 61 years), healthy and without regular intake of medicine were investigated two times: (1) During continuous isotonic saline infusion (C-Saline) and (2) during continuous Escherichia coli endotoxin (10,000 USP Endotoxin, lot HOK354; The United States Pharmacopeial Convention, Inc.) infusion of $0.06 \mathrm{ng} / \mathrm{kg}$ of body weight per hour (C-LPS). Each study day lasted $4 \mathrm{~h}$, and the study days were separated by at least one month. The continuous infusion started at $t=0 \mathrm{~min}$. Arterialized blood was sampled at $t=0,120$ and 240 min for FGF21 analysis.

Both studies were conducted in accordance with the Declaration of Helsinki, and all study subjects gave their oral and written informed consent to participate in the trial. The study protocols were approved by the Local Ethics Committee.

\section{Blood samples and measurement}

Blood was collected in $3.5 \mathrm{~mL}$ vacutainers and immediately centrifuged at $2500 \boldsymbol{g}$ for $10 \mathrm{~min}$ at $4^{\circ} \mathrm{C}$.

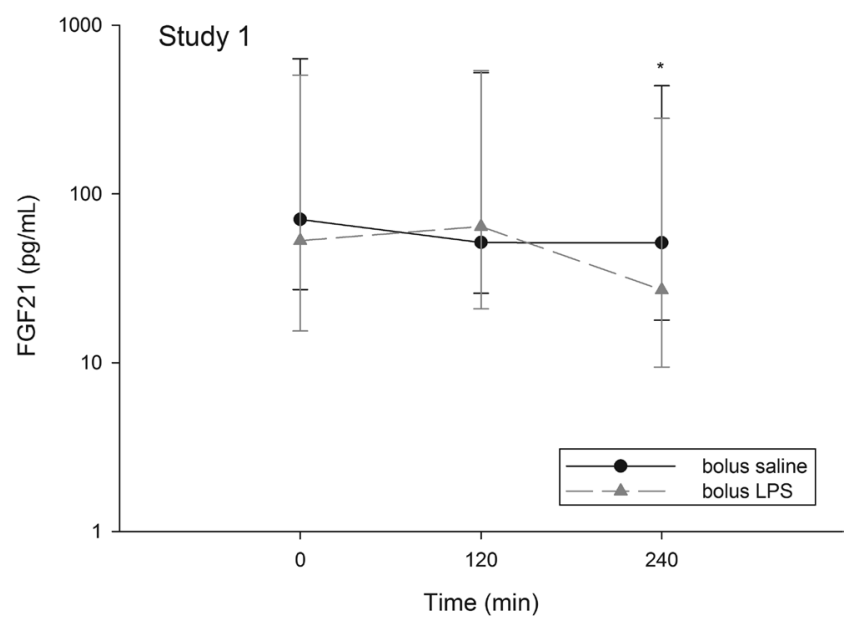

Figure 1

Healthy males $(n=8)$ underwent two interventions: (1) isotonic saline injection (bolus saline) and (2) a LPS bolus injection (bolus LPS). The graph depicts FGF21 concentrations $(\mathrm{pg} / \mathrm{mL})$ during the two conditions. The $Y$-axis is logarithmic scaled. Points are medians and error bars are ranges. $* P<0.05$. 
Table 1 Delta values for cytokines and vital parameters in study 1 for the study days: (1) isotonic saline injection (bolus saline) and (2) LPS bolus injection (bolus LPS).

\begin{tabular}{|c|c|c|c|c|}
\hline & Unit & Bolus saline & Bolus LPS & $P$ value \\
\hline$\Delta \mathrm{IL}-1 \beta$ & $\mathrm{pg} / \mathrm{mL}$ & $1.3(0.0-5.8)$ & 8.8 (7.3-15.3) & NS \\
\hline$\Delta \mathrm{IL}-6$ & $\mathrm{pg} / \mathrm{mL}$ & $4.1(2.0-10.5)$ & 1166 (1016-1651) & $<0.0001$ \\
\hline$\Delta \mathrm{IL}-10$ & $\mathrm{pg} / \mathrm{mL}$ & $1.3(0.0-3.3)$ & $62.5(41-102)$ & $<0.0001$ \\
\hline$\Delta$ TNF- $\alpha$ & $\mathrm{pg} / \mathrm{mL}$ & $18(15-21)$ & 467 (370-613) & $<0.0001$ \\
\hline$\Delta$ Temperature & ${ }^{\circ} \mathrm{C}$ & $0.6 \pm 0.12$ & $2.8 \pm 0.24$ & $<0.0001$ \\
\hline$\Delta$ Heart rate & Beats per minute & $7.8 \pm 1.1$ & $36.5 \pm 1.9$ & $<0.0001$ \\
\hline$\triangle \mathrm{MAP}$ & $\mathrm{mmHg}$ & $-6.3 \pm 2.7$ & $-5.8 \pm 2.0$ & NS \\
\hline
\end{tabular}

Delta values $(\Delta)$ are calculated by subtracting the baseline value (time $=0 \mathrm{~min}$ ) from the maximal value (measured at 60,180 , and $300 \mathrm{~min}$ ). One-way repeated measures ANOVA and Bonferroni corrected post hoc analysis were used to compare groups. Data are shown as mean \pm S.E. and as median (interquartile range; $25-75 \%$ ).

MAP, mean arterial pressure; NS, not significant.

Serum was then transferred to $2 \mathrm{~mL}$ micro tubes and stored at $-80^{\circ} \mathrm{C}$ until analysis.

Human serum FGF21 was quantified by commercially available monoclonal antibodies (R\&D Systems, DY2539) modified to time-resolved immunoflourometric assay. Briefly, wells were coated with $0.2 \mu \mathrm{g}$ anti-FGF21 antibody in $100 \mu \mathrm{L}$ phosphate buffered saline (PBS) overnight at $4^{\circ} \mathrm{C}$. Residual protein-binding sites in the wells were blocked with 1\% Tween20 in PBS for $1 \mathrm{~h}$ at room temperature and washed in PBS containing 0.05\% Tween 20 (PBS/Tw). Recombinant FGF21 in the range from 3.9 to $500 \mathrm{ng} / \mathrm{L}$ was used as standard. Serum samples were diluted 4-fold in PBS with $1 \%$ bovine serum albumin (BSA) (SigmaAldrich) and incubated overnight at $4^{\circ} \mathrm{C}$. All samples from each subject were analyzed on the same plate to avoid inter-assay variation. Bound FGF21 was determined by incubation with $10 \mathrm{ng}$ biotinylated anti-FGF21 detection antibody in $100 \mu \mathrm{L}$ PBS with 1\% BSA at room temperature

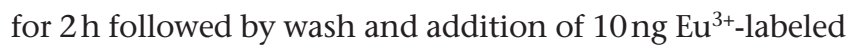
streptavidin (Perkin Elmer) in $100 \mu \mathrm{L}$ PBS/Tw containing $25 \mu \mathrm{M}$ EDTA for $1 \mathrm{~h}$ at room temperature. After wash, bound europium was detected by the addition of $200 \mu \mathrm{L}$ of enhancement solution (Perkin Elmer), 5 min of vigorous shaking and reading the time-resolved fluorescence on a DELFIA fluorometer (Victor ${ }^{3}$, Perkin Elmer). The limit of detection was $1 \mathrm{pg} / \mathrm{mL}$. The intra- and inter-assay variations (\%CV) were below 6 and 10\%, respectively.

\section{Statistics}

Normal distribution was assessed by QQ plots using Stata 13.1 (StataCorp LP). Study 1 results are not normally distributed and are thus expressed as medians (range), and the statistical analysis was performed on logarithmic transformed normally distributed data (not shown). Normal distribution is achieved by excluding one

$\begin{array}{lr}\text { http://www.endocrineconnections.org } & \text { ○ } 2017 \text { The authors } \\ \text { DOI: } 10.1530 / E C-16-0103 & \text { Published by Bioscientifica Ltd }\end{array}$

outlying study subject, but we had no reasons to do so as wide inter-individual variance is a well-known issue for FGF21 (24). For Study 2, results are normally distributed and thus expressed as means \pm S.E. The statistical analyses were performed by using SigmaPlot 11.0 (Systat Software, Inc.). A two-way ANOVA (time $\times$ treatment) for repeated measurements with Student-Newman-Keuls method as post hoc analysis was used to test for differences between both groups in both trials. $P<0.05$ was considered statistically significant.

\section{Results}

\section{Study 1}

Overall, serum FGF21 levels were significantly different between saline and LPS (timextreatment interaction,

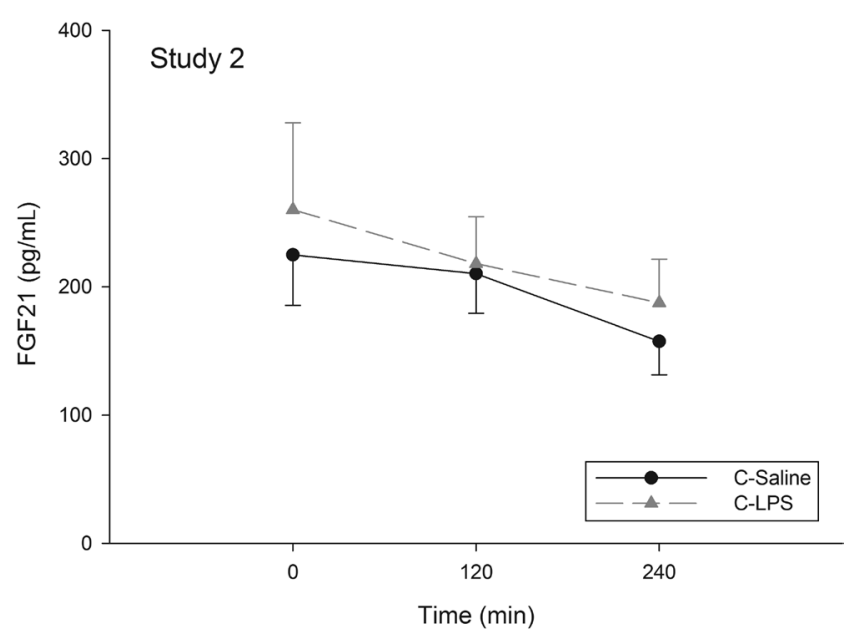

Figure 2

Healthy males $(n=8)$ underwent two interventions: (1) isotonic saline injection (C-Saline) and (2) continuous LPS infusion (C-LPS). The graph depicts FGF21 concentrations $(\mathrm{pg} / \mathrm{mL}$ ) during the two conditions. Points are means \pm S.E. No statistical difference was detected. 
$P=0.004$ ) (Fig. 1). Post hoc analysis revealed significant difference of the intervention at $t=240 \mathrm{~min}$ where serum FGF21 was significantly lower after bolus LPS (27.0 (9.4$280.9) \mathrm{pg} / \mathrm{mL}$ ) vs bolus saline (51.3 (17.8-436.7) $\mathrm{pg} / \mathrm{mL})$, $P=0.035$. The suppression in FGF21 was $>50 \%$ of the concentration from $t=120 \mathrm{~min}$ in $6 / 8$ of the study subjects, and only one study subject did not decline (data now shown).

Table 1 list extracted vital parameters and cytokine response to LPS; for the full metabolic response, see the primary article (22).

\section{Study 2}

Overall, serum FGF21 levels were not significantly different between C-Saline and C-LPS (time $\times$ treatment interaction, $P=0.82$ ) (Fig. 2); thus, no post hoc analysis was performed.

In this study, we did not achieve an APR reaction; for the full metabolic response, see the primary article (23).

\section{Discussion}

The aim of this investigation was to explore the acute effect of LPS on FGF21 levels. We report a late suppression in serum FGF21 after a LPS bolus in Study 1. It is teleologically meaningful if FGF21 levels are suppressed during acute inflammation permitting the metabolic consequences to be established. FGF21 has also lately been recognized to directly inhibit macrophage-mediated inflammation (25), which also makes suppression in the acute state meaningful. In Study 2, we did not find the same suppression. We believe this is explained by a much lower accumulated LPS dose $(0.24 \mathrm{ng} / \mathrm{kg}$ accumulated over $4 \mathrm{~h}$ vs $1 \mathrm{ng} / \mathrm{kg}$ instantaneously), and thus, not an APR powerful enough to influence FGF21 kinetics. In study 1, we did not find increased FGF21 levels despite a sufficient inflammatory response and we can therefore exclude FGF21 as a rapid ( $<4 \mathrm{~h}$ ) biomarker of LPS-induced inflammation. Our findings for Study 1 are not consistent with the previous results in mice in which no difference in FGF21 levels was detected $4 \mathrm{~h}$ after LPS injection (19).

Sixteen hours after injection in mice, an increase in FGF21 was reported (19), and increased FGF21 levels were reported in patients with sepsis or SIRS (21). However, in our study, no blood was sampled later than $4 \mathrm{~h}$ after LPS exposure, and we are unable to confirm a possible late increase in humans. The late increase is probably explained by either directstimulation through inflammatory cytokines, reduced clearance or it may be provoked by increased FFA and glucose levels $(16,17)$. The source of FGF21 during the APR in mice seems to be white adipose tissue and skeletal muscle (19). As synthesis of FGF21 in white adipose tissue cell lines was not stimulated by cytokines (19), and we actually found a suppression in human serum FGF21 after LPS bolus exposure, we believe that the late inflammatory FGF21 response in both mice and human is caused by the secondary metabolic effects to the APR, but further studies are required to confirm this hypothesis.

There are certain limitations to our study. First, we cannot exclude that the dose of LPS was too low to induce an APR powerful enough to increase FGF21 levels, but given the clinical affection of our study subjects in Study 1 (Table 1), this is unlikely. Another limitation is the study period that is too short to catch effects beyond $4 \mathrm{~h}$ from LPS exposure. A final limitation is the well-known wide inter-individual variance (24) that we specifically encountered in Study 1.

\section{Conclusion}

Our studies show that a LPS bolus results in decreased FGF21 levels $4 \mathrm{~h}$ from exposure. This suggests that the late increase in FGF21 is regulated by the metabolic adaptations to the APR and that FGF21 is not a part of the APR itself.

\section{Declaration of interest}

The authors declare that there is no conflict of interest that could be perceived as prejudicing the impartiality of the research reported.

\section{Funding}

The study received support from the Danish Council for Strategic Research ('Keto-group' - \# 0603-00479B). The study was also supported by a pregraduate scholarship (4004-00007B) from the Danish Council for Independent Research (Medical Sciences).

\section{Acknowledgements}

The authors would like to thank Lisa Buss, The Medical Research Laboratories, Institute of Clinical Research, Aarhus University, for invaluable technical assistance.

\section{References}

1 Kharitonenkov A, Shiyanova TL, Koester A, Ford AM, Micanovic R, Galbreath EJ, Sandusky GE, Hammond LJ, Moyers JS, Owens RA, et al. FGF-21 as a novel metabolic regulator. Journal of Clinical Investigation 2005115 1627-1635. (doi:10.1172/jci23606)

2 Kharitonenkov A, Wroblewski VJ, Koester A, Chen YF, Clutinger CK, Tigno XT, Hansen BC, Shanafelt AB \& Etgen GJ. The metabolic

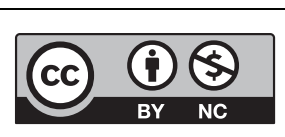

This work is licensed under a Creative Commons Attribution-NonCommercial 4.0 International License. 
state of diabetic monkeys is regulated by fibroblast growth factor-21. Endocrinology 2007148 774-781. (doi:10.1210/ en.2006-1168)

3 Badman MK, Pissios P, Kennedy AR, Koukos G, Flier JS \& Maratos-Flier E. Hepatic fibroblast growth factor 21 is regulated by PPARalpha and is a key mediator of hepatic lipid metabolism in ketotic states. Cell Metabolism 20075 426-437. (doi:10.1016/j. cmet.2007.05.002)

4 Coskun T, Bina HA, Schneider MA, Dunbar JD, Hu CC, Chen Y, Moller DE \& Kharitonenkov A. Fibroblast growth factor 21 corrects obesity in mice. Endocrinology 2008149 6018-6027. (doi:10.1210/ en.2008-0816)

5 Inagaki T, Dutchak P, Zhao G, Ding X, Gautron L, Parameswara V, Li Y, Goetz R, Mohammadi M, Esser V, et al. Endocrine regulation of the fasting response by PPARalpha-mediated induction of fibroblast growth factor 21. Cell Metabolism 20075 415-425. (doi:10.1016/j. cmet.2007.05.003)

6 Nishimura T, Nakatake Y, Konishi M \& Itoh N. Identification of a novel FGF, FGF-21, preferentially expressed in the liver. Biochimica et Biophysica Acta 20001492 203-206. (doi:10.1016/S01674781(00)00067-1)

7 Lundasen T, Hunt MC, Nilsson LM, Sanyal S, Angelin B, Alexson SE \& Rudling M. PPARalpha is a key regulator of hepatic FGF21. Biochemical and Biophysical Research Communications 2007360 437-440. (doi:10.1016/j.bbrc.2007.06.068)

8 Muise ES, Azzolina B, Kuo DW, El-Sherbeini M, Tan Y, Yuan X, $\mathrm{Mu}$ J, Thompson JR, Berger JP \& Wong KK. Adipose fibroblast growth factor 21 is up-regulated by peroxisome proliferator-activated receptor gamma and altered metabolic states. Molecular Pharmacology 200874 403-412. (doi:10.1124/mol.108.044826)

9 Hojman P, Pedersen M, Nielsen AR, Krogh-Madsen R, Yfanti C, Akerstrom T, Nielsen S \& Pedersen BK. Fibroblast growth factor-21 is induced in human skeletal muscles by hyperinsulinemia. Diabetes 200958 2797-2801. (doi:10.2337/db09-0713)

10 Chakravarthy MV, Pan Z, Zhu Y, Tordjman K, Schneider JG, Coleman T, Turk J \& Semenkovich CF. 'New' hepatic fat activates PPARalpha to maintain glucose, lipid, and cholesterol homeostasis. Cell Metabolism 20051 309-322. (doi:10.1016/j. cmet.2005.04.002)

11 Christodoulides C, Dyson P, Sprecher D, Tsintzas K \& Karpe F. Circulating fibroblast growth factor 21 is induced by peroxisome proliferator-activated receptor agonists but not ketosis in man. Journal of Clinical Endocrinology and Metabolism 200994 3594-3601. (doi:10.1210/jc.2009-0111)

12 Dushay JR, Toschi E, Mitten EK, Fisher FM, Herman MA \& Maratos-Flier E. Fructose ingestion acutely stimulates circulating FGF21 levels in humans. Molecular Metabolism 2014 4 51-57. (doi:10.1016/j.molmet.2014.09.008)

13 Chavez AO, Molina-Carrion M, Abdul-Ghani MA, Folli F, Defronzo RA \& Tripathy D. Circulating fibroblast growth factor-21 is elevated in impaired glucose tolerance and type 2 diabetes and correlates with muscle and hepatic insulin resistance. Diabetes Care 200932 1542-1546. (doi:10.2337/dc09-0684)
14 Dushay J, Chui PC, Gopalakrishnan GS, Varela-Rey M, Crawley M, Fisher FM, Badman MK, Martinez-Chantar ML \& Maratos-Flier E. Increased fibroblast growth factor 21 in obesity and nonalcoholic fatty liver disease. Gastroenterology 2010139 456-463. (doi:10.1053/j. gastro.2010.04.054)

15 Zhang X, Yeung DC, Karpisek M, Stejskal D, Zhou ZG, Liu F, Wong RL, Chow WS, Tso AW, Lam KS, et al. Serum FGF21 levels are increased in obesity and are independently associated with the metabolic syndrome in humans. Diabetes 200857 1246-1253. (doi:10.2337/ db07-1476)

16 Khovidhunkit W, Kim MS, Memon RA, Shigenaga JK, Moser AH, Feingold KR \& Grunfeld C. Effects of infection and inflammation on lipid and lipoprotein metabolism: mechanisms and consequences to the host. Journal of Lipid Research 200445 1169-1196. (doi:10.1194/ jlr.R300019-JLR200)

17 Chambrier C, Laville M, Rhzioual Berrada K, Odeon M, Bouletreau P \& Beylot M. Insulin sensitivity of glucose and fat metabolism in severe sepsis. Clinical Science 200099 321-328. (doi:10.1042/cs0990321)

18 Baumann H \& Gauldie J. The acute phase response. Immunology Today 199415 74-80. (doi:10.1016/0167-5699(94)90137-6)

19 Feingold KR, Grunfeld C, Heuer JG, Gupta A, Cramer M, Zhang T, Shigenaga JK, Patzek SM, Chan ZW, Moser A, et al. FGF21 is increased by inflammatory stimuli and protects leptin-deficient ob/ob mice from the toxicity of sepsis. Endocrinology 2012153 2689-2700. (doi:10.1210/en.2011-1496)

20 Johnson CL, Weston JY, Chadi SA, Fazio EN, Huff MW, Kharitonenkov A, Koester A \& Pin CL. Fibroblast growth factor 21 reduces the severity of cerulein-induced pancreatitis in mice. Gastroenterology 2009137 1795-1804. (doi:10.1053/j.gastro.2009.07.064)

21 Gariani K, Drifte G, Dunn-Siegrist I, Pugin J \& Jornayvaz FR. Increased FGF21 plasma levels in humans with sepsis and SIRS. Endocrine Connections 20132 146-153. (doi:10.1530/EC-13-0040)

22 Rittig N, Bach E, Thomsen HH, Johannsen M, Jorgensen JO, Richelsen B, Jessen N \& Moller N. Amino acid supplementation is anabolic during the acute phase of endotoxin-induced inflammation: a human randomized crossover trial. Clinical Nutrition 201635 322-330. (doi:10.1016/j.clnu.2015.03.021)

23 Bach E, Moller AB, Jorgensen JO, Vendelbo MH, Jessen N, Pedersen SB, Nielsen TS \& Moller N. Stress hormone release is a key component of the metabolic response to lipopolysaccharide (LPS): studies in hypopituitary and healthy subjects. European Journal of Endocrinology 2016175 455-465. (doi:10.1530/EJE-16-0444)

24 Galman C, Lundasen T, Kharitonenkov A, Bina HA, Eriksson M, Hafstrom I, Dahlin M, Amark P, Angelin B \& Rudling M. The circulating metabolic regulator FGF21 is induced by prolonged fasting and PPARalpha activation in man. Cell Metabolism 20088 169-174. (doi:10.1016/j.cmet.2008.06.014)

25 Yu Y, He J, Li S, Song L, Guo X, Yao W, Zou D, Gao X, Liu Y, Bai F, et al. Fibroblast growth factor 21 (FGF21) inhibits macrophagemediated inflammation by activating Nrf2 and suppressing the NF-kappaB signaling pathway. International Immunopharmacology 2016 38 144-152. (doi:10.1016/j.intimp.2016.05.026)

Received in final form 27 November 2016

Accepted 9 January 2017

Accepted Preprint published online 9 January 2017 http://www.endocrineconnections.org DOI: 10.1530/EC-16-0103 (c) 2017 The authors Published by Bioscientifica Ltd

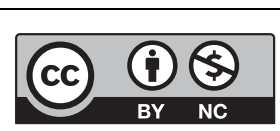

This work is licensed under a Creative Commons Attribution-NonCommercial 4.0 International License. 